\title{
Case Report \\ Long-Term Intravenous Ketamine for Analgesia in a Child with Severe Chronic Intestinal Graft versus Host Disease
}

\author{
Jennifer Busse, ${ }^{1}$ Leroy Phillips, ${ }^{2}$ and William Schechter ${ }^{3}$ \\ ${ }^{1}$ Anesthesiology, Morgan Stanley Children's Hospital at Columbia University, New York, NY 10032, USA \\ ${ }^{2}$ Anesthesiology, New York University Langone Medical Center, New York, NY 10016, USA \\ ${ }^{3}$ Anesthesiology and Pediatrics, Morgan Stanley Children's Hospital at Columbia University, New York, NY 10032, USA \\ Correspondence should be addressed to Jennifer Busse; jab2243@cumc.columbia.edu
}

Received 29 September 2015; Accepted 29 November 2015

Academic Editor: Jian-jun Yang

Copyright (C) 2015 Jennifer Busse et al. This is an open access article distributed under the Creative Commons Attribution License, which permits unrestricted use, distribution, and reproduction in any medium, provided the original work is properly cited.

Ketamine is reported to be an effective adjuvant to opioids in the treatment of refractory cancer pain; however, the use of high doses of ketamine for extended periods in pediatric patients has not been described. We present a five-year-old male with grade IV intestinal GVHD whose abdominal pain required both hydromorphone and ketamine for a period of over four months. There was no evidence of hepatotoxicity, hemorrhagic cystitis, or other adverse effects. Possible withdrawal symptoms were mild and were readily mitigated by gradually weaning ketamine.

\section{Introduction}

Chronic pain related to gastrointestinal graft versus host disease (GVHD) is often difficult to treat, causing a significant decrease in quality of life [1]. The pain is characterized as sharp or cramping and is attributed to inflammation, edema, increased mucosal friability, and ileus [2]. GVHD symptoms present as anorexia, nausea, vomiting, diarrhea, and cholestasis and may be accompanied by a maculopapular rash. Opioids are commonly utilized to treat the chronic pain related to GVHD, but their efficacy is limited by associated adverse effects, including sedation [3], immunosuppression [4], nausea, vomiting, and ileus. Nonsteroidal anti-inflammatories (NSAIDs) or acetaminophen may be contraindicated because of hepatic insufficiency or coagulopathy.

Ketamine has been reported to be effective as an adjuvant to opioids in the treatment of chronic refractory cancer pain [5-7]. It is an N-methyl-D-aspartate (NMDA) receptor antagonist which induces synthesis and release of nitric oxide and indirectly modulates mu opioid receptor signaling [8, 9]. In chronic pain, ketamine reduces central sensitization [10] and decreases the development of opioid tolerance [11]. Doses of $0.2 \mathrm{mg} / \mathrm{kg} / \mathrm{h}$ to $0.5 \mathrm{mg} / \mathrm{kg} / \mathrm{h}$ of IV ketamine given for short periods have been shown to be safe and opioidsparing in pediatric patients [12]. Studies in adults have shown long-term control of cancer-related pain via the oral [13-16], intravenous (IV), or subcutaneous route [16-19]. Common adverse effects associated with ketamine include blurred vision, sialorrhea, anorexia, depression, hypertension, insomnia, anxiety, and visual and dream disturbances [19-21]. Long-term administration of ketamine may be associated with transaminitis and ulcerative or hemorrhagic cystitis $[22,23]$. Its use is contraindicated in patients with increased intracranial or intraocular pressure.

There have been few studies on the use of ketamine in pediatric patients and only one prospective study of longterm ketamine use for chronic pain in pediatric patients via oral administration $[12,13]$. The only case study of long-term administration of intravenous ketamine in pediatric patients was over a period of nine weeks to treat cancer pain. The dose administered was not reported, and side effects observed included myoclonic movements [24]. Previous case studies among adults who chronically misused ketamine for many months have variously reported withdrawal symptoms [25, 26]. Abrupt ketamine discontinuation has been shown to increase allodynia, hyperalgesia, sleep disorders, and anxiety in adults [27-29]. Higher dose ketamine for treatment of pain in pediatric patients over an extended time period has not been reported. We now report the use of higher dose ketamine infusion for a prolonged period to treat pain 
associated with GVHD in a 5-year-old child without evidence of toxicity, tolerance, or signs of withdrawal during infusion.

\section{Case Description}

A five-year-old 27.5 kilogram male with history of highrisk acute myeloid leukemia received a matched unrelated donor transplant at an outside institution. His course was complicated by persistent vancomycin resistant Enterococcus infection and grade IV chronic intestinal GVHD refractory to multiple therapies. He was transferred to our institution specifically for treatment of GVHD using a mesenchymal stem cell therapy (MSC) protocol [30, 31]. Epidural infusion of a local anesthetic and an opioid initially provided excellent control of abdominal pain. Because of persistent fevers, the epidural was discontinued and the patient was treated with hydromorphone utilizing patient controlled analgesia (PCA) but required the subsequent addition of a ketamine infusion that was incrementally titrated to higher doses. Just prior to transfer to our institution, his abdominal pain was well controlled on $28 \mathrm{mg}$ per day of hydromorphone and $0.54 \mathrm{mg} / \mathrm{kg} / \mathrm{h}$ of ketamine which had been slowly titrated up by an outside hospital over four months. The patient remained on ketamine at our institution for an additional 6 weeks.

Abdominal pain was described as constant, of severe intensity, and cramping extending from the suprapubic area to the umbilicus. When ketamine was significantly reduced to $0.054 \mathrm{mg} / \mathrm{kg} / \mathrm{h}(0.9 \mathrm{mcg} / \mathrm{kg} / \mathrm{min})$ after his transfer, pain scores increased significantly. When raised back to $0.54 \mathrm{mg} / \mathrm{kg} / \mathrm{h}$ ( $9 \mathrm{mcg} / \mathrm{kg} / \mathrm{min})$, pain control was regained. On exam, bowel sounds were hyperactive and the abdomen was tender and distended but without rebound tenderness. There was mild hepatomegaly, but no evidence of free or intramural intestinal air. Mental status was normal and he was not overly sedated. There was no diplopia, sialorrhea, or hematuria. Despite treatment, he had persistent vomiting and unremitting diarrhea. Blood pressure was elevated upon admission and remained so with an average of 120/80, which is approximately the 99th percentile for his age. Hypertension was thought to be related to tacrolimus and/or steroids. Hypertension was treated with a clonidine patch, carvedilol, amlodipine, furosemide, and enalapril.

Upon admission, a CT scan of the abdomen and pelvis showed bowel wall thickening. Liver function testing was closely monitored during ketamine treatment both for toxicity and for signs of venoocclusive disease or GVHD of the liver. Alanine aminotransferase never exceeded normal values; however, aspartate aminotransferase was mildly elevated but stable from before his transfer. Total, direct, and indirect bilirubin were also mildly elevated, but never to more than $10 \%$ of the upper limit of normal. Alkaline phosphatase and lactate dehydrogenase were both persistently elevated averaging $275 \mathrm{U} / \mathrm{L}$ and $580 \mathrm{~g} / \mathrm{dL}$. Liver function enzymes returned to normal levels within one week of discontinuation of ketamine and completion of the MSC protocol.

Clinical improvement in GVHD was noted with MSC therapy. Opioid dosing via PCA was weaned by approximately $20 \%$ of the total daily dose every 48 hours. On alternate days, the ketamine infusion dose was reduced by $1 \mathrm{mcg} / \mathrm{kg} / \mathrm{minute}$ with no recrudescence of abdominal pain. Mild irritability and restlessness were noted as the opioid and ketamine were weaned. These symptoms resolved within 3 days of discontinuance of ketamine and IV opioids. It was not clear whether this represented a distinct ketamine withdrawal phenomenon; however, there was no increase in the number of bowel movements, nausea, or tremors to suggest opioid withdrawal. A clonidine patch remained in place throughout the weaning process.

\section{Discussion}

Pain related to gastrointestinal GVHD can be persistent and difficult to treat. Ketamine is an excellent adjuvant for the management of chronic cancer pain [3, 12-18], but never specifically as a treatment for pain associated with GVHD in pediatrics. Safe dose limits, duration of treatment, or a withdrawal syndrome have not been established in pediatrics. In this case, ketamine was an excellent adjuvant to hydromorphone, providing a clinically observable improvement in pain scores and a plateau in total opioid requirement. This may be related to the additional analgesia provided by ketamine, as well as ketamine's mitigating effects on the development of opioid tolerance. Ketamine may have also prevented the development of gastroenteric nerve sensitization and hyperalgesia, due to inhibition of inflammatory cytokines known to accompany GVHD [31].

NSAIDs and acetaminophen were contraindicated because of risk of bleeding and hepatotoxicity risks. Tricyclic antidepressants, SSRIs, and anticonvulsants could not be used because the enteral route was not reliably available. A ketamine infusion was selected over other pharmacologic pain treatment modalities including a lidocaine infusion because the risk of an adverse event was thought to be less.

Ketamine infused at higher doses for longer periods of time than previously reported appeared to be safe in this patient. Our case also shows that tolerance to ketamine may develop over time. Theoretically, a mild withdrawal syndrome may have been mitigated to some extent by the use of clonidine, an alpha 2 agonist. Clonidine modulates the presynaptic release of norepinephrine [32]; therefore, one might speculate that its presence might affect ketamine withdrawal, since ketamine is known to increase endogenous norepinephrine release [33]. Resolution of abnormal liver function occurred after discontinuation of ketamine. However, since the patient had abnormal liver function even before the initiation of ketamine administration, it is unlikely that this was related to the use of ketamine. Our case illustrates that long-term administration of ketamine may be associated with very little significant adverse effects in some patients. Therefore, long-term administration of ketamine appeared safe in this case and may be considered in severe, refractory pain syndromes associated with GVHD but may require careful uptitration over time. It is important to emphasize that the patient should be closely monitored for excessive sedation, liver toxicity, hematuria, hypertension, tachycardia, or psychomimetic effects. Slow weaning is recommended to prevent the manifestation of withdrawal symptoms. 


\section{Consent}

On $4 / 2 / 2015$, the authors reviewed the case report with the patient's mother who gave written permission for the authors to publish this report.

\section{Conflict of Interests}

The authors declare that there is no conflict of interests regarding the publication of this paper.

\section{References}

[1] U. Forinder, C. Löf, and J. Winiarski, "Quality of life and health in children following allogeneic SCT," Bone Marrow Transplantation, vol. 36, no. 2, pp. 171-176, 2005.

[2] G. Akpek, W. Chinratanalab, L. A. Lee et al., "Gastrointestinal involvement in chronic graft-versus-host disease: a clinicopathologic study," Biology of Blood and Marrow Transplantation, vol. 9, no. 1, pp. 46-51, 2003.

[3] S. Mercadante, E. Arcuri, W. Tirelli, and A. Casuccio, "Analgesic effect of intravenous ketamine in cancer patients on morphine therapy: a randomized, controlled, double-blind, crossover, double-dose study," Journal of Pain and Symptom Management, vol. 20, no. 4, pp. 246-252, 2000.

[4] D. Yin, R. A. Mufson, R. Wang, and Y. Shi, "Fas-mediated cell death promoted by opioids," Nature, vol. 397, article 218, 1999.

[5] R. F. Bell, C. Eccleston, and E. Kalso, "Ketamine as adjuvant to opioids for cancer pain. A qualitative systematic review," Journal of Pain and Symptom Management, vol. 26, no. 3, pp. 867-875, 2003.

[6] R. F. Bell, "Ketamine for chronic non-cancer pain," Pain, vol. 141, no. 3, pp. 210-214, 2009.

[7] T. Okon, "Ketamine: an introduction for the pain and palliative medicine physician," Pain Physician, vol. 10, no. 3, pp. 493-500, 2007.

[8] A. K. Mehta, S. Halder, N. Khanna, O. P. Tandon, and K. K. Sharma, "Antagonism of stimulation-produced analgesia by naloxone and $\mathrm{N}$-methyl-D-aspartate: role of opioid and $\mathrm{N}$ methyl-D-aspartate receptors," Human and Experimental Toxicology, vol. 31, no. 1, pp. 51-56, 2012.

[9] A. Gupta, L. A. Devi, and I. Gomes, "Potentiation of $\mu$ opioid receptor-mediated signaling by ketamine," Journal of Neurochemistry, vol. 119, no. 2, pp. 294-302, 2011.

[10] A. Latremoliere and C. J. Woolf, "Central sensitization: a generator of pain hypersensitivity by central neural plasticity," Journal of Pain, vol. 10, no. 9, pp. 895-926, 2009.

[11] M. Luginbühl, A. Gerber, T. W. Schnider, S. Petersen-Felix, L. Arendt-Nielsen, and M. Curatolo, "Modulation of remifentanilinduced analgesia, hyperalgesia, and tolerance by small-dose ketamine in humans," Anesthesia and Analgesia, vol. 96, no. 3, pp. 726-732, 2003.

[12] A. L. Bredlau, R. Thakur, D. N. Korones, and R. H. Dworkin, "Ketamine for pain in adults and children with cancer: a systematic review and synthesis of the literature," Pain Medicine, vol. 14, no. 10, pp. 1505-1517, 2013.

[13] A.-L. Bredlau, M. P. McDermott, H. R. Adams et al., "Oral ketamine for children with chronic pain: a pilot phase 1 study," Journal of Pediatrics, vol. 163, no. 1, pp. 194-200, 2013.

[14] M. J. Sigtermans, J. J. van Hilten, M. C. R. Bauer et al., "Ketamine produces effective and long-term pain relief in patients with complex regional pain syndrome type 1," Pain, vol. 145, no. 3, pp. 304-311, 2009.

[15] R. J. Schwartzman, G. M. Alexander, J. R. Grothusen, T. Paylor, E. Reichenberger, and M. Perreault, "Outpatient intravenous ketamine for the treatment of complex regional pain syndrome: a double-blind placebo controlled study," Pain, vol. 147, no. 1-3, pp. 107-115, 2009.

[16] G. R. Lauretti, I. C. Lima, M. P. Reis, W. A. Prado, and N. L. Pereira, "Oral ketamine and transdermal nitroglycerin as analgesic adjuvants to oral morphine therapy for cancer pain," Anesthesiology, vol. 90, no. 6, pp. 1528-1533, 1999.

[17] G. R. Lauretti, J. M. A. Gomes, M. P. Reis, and N. L. Pereira, "Low doses of epidural ketamine or neostigmine, but not midazolam, improve morphine analgesia in epidural terminal cancer pain therapy," Journal of Clinical Anesthesia, vol. 11, no. 8, pp. 663668, 1999.

[18] J. C. Finkel, S. R. Pestieau, and Z. M. N. Quezado, "Ketamine as an adjuvant for treatment of cancer pain in children and adolescents," Journal of Pain, vol. 8, no. 6, pp. 515-521, 2007.

[19] M. Conway, N. White, C. S. Jean, W. T. Zempsky, and K. Steven, "Use of continuous intravenous ketamine for end-stage cancer pain in children," Journal of Pediatric Oncology Nursing, vol. 26, no. 2, pp. 100-106, 2009.

[20] B. C. H. Tsui, D. Davies, S. Desai, and S. Malherbe, "Intravenous ketamine infusion as an adjuvant to morphine in a 2-yearold with severe cancer pain from metastatic neuroblastoma," Journal of Pediatric Hematology/Oncology, vol. 26, no. 10, pp. 678-680, 2004.

[21] M. I. Blonk, B. G. Koder, P. M. van den Bemt, and F. J. P. M. Huygen, "Use of oral ketamine in chronic pain management: a review," European Journal of Pain, vol. 14, no. 5, pp. 466-472, 2010.

[22] J. Hardy, S. Quinn, B. Fazekas et al., "Randomized, double-blind, placebo-controlled study to assess the efficacy and toxicity of subcutaneous ketamine in the management of cancer pain," Journal of Clinical Oncology, vol. 30, no. 29, pp. 3611-3617, 2012.

[23] I. M. Noppers, M. Niesters, L. P. H. J. Aarts et al., "Drug-induced liver injury following a repeated course of ketamine treatment for chronic pain in CRPS type 1 patients: a report of 3 cases," Pain, vol. 152, no. 9, pp. 2173-2178, 2011.

[24] P. Klepstad, P. Borchgrevink, B. Hval, S. Flaat, and S. Kaasa, "Long-term treatment with ketamine in a 12-year-old girl with severe neuropathic pain caused by a cervical spinal tumor," Journal of Pediatric Hematology/Oncology, vol. 23, no. 9, pp. 616619, 2001.

[25] D. G. Critchlow, "A case of ketamine dependence with discontinuation symptoms," Addiction, vol. 101, no. 8, pp. 1212-1213, 2006.

[26] J. X. Liu, E. Zerbo, and S. Ross, "Intensive ketamine use for multiple years: a case report," The American Journal on Addictions, vol. 24, no. 1, pp. 7-9, 2015.

[27] J. L. Walgren, M. A. Carfagna, D. Koger, M. Sgro, and M. J. Kallman, "Withdrawal assessment following subchronic oral ketamine administration in cynomolgus macaques," Drug Development Research, vol. 75, no. 3, pp. 162-171, 2014.

[28] M. Błachut, K. Sołowiów, A. Janus et al., "A case of ketamine dependence," Psychiatria Polska, vol. 43, no. 5, pp. 593-599, 2009.

[29] A. C. Mitchell, "Generalized hyperalgesia and allodynia following abrupt cessation of subcutaneous ketamine infusion," Palliative Medicine, vol. 13, no. 5, pp. 427-428, 1999. 
[30] J. Stagg and J. Galipeau, "Mechanisms of immune modulation by mesenchymal stromal cells and clinical translation," Current Molecular Medicine, vol. 13, no. 5, pp. 856-867, 2013.

[31] C. B. Berde and N. F. Sethna, "Analgesics for the treatment of pain in children," The New England Journal of Medicine, vol. 347, no. 14, pp. 1094-1103, 2002.

[32] G. K. Aghajanian and C. P. VanderMaelen, "Alpha 2-adrenoceptor-mediated hyperpolarization of locus coeruleus neurons: intracellular studies in vivo," Science, vol. 215, no. 4538, pp. 13941396, 1982.

[33] T. Kushikata, H. Yoshida, M. Kudo, T. Kudo, T. Kudo, and K. Hirota, "Role of coerulean noradrenergic neurones in general anaesthesia in rats," British Journal of Anaesthesia, vol. 107, no. 6, pp. 924-929, 2011. 


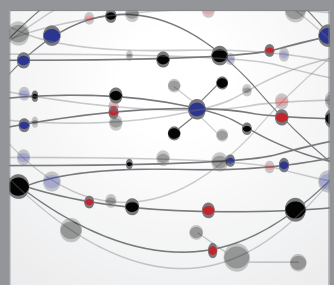

The Scientific World Journal
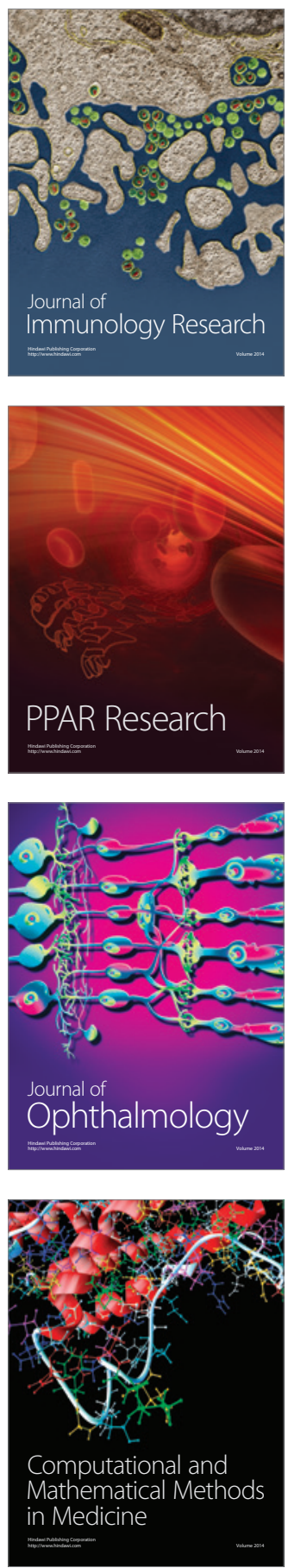

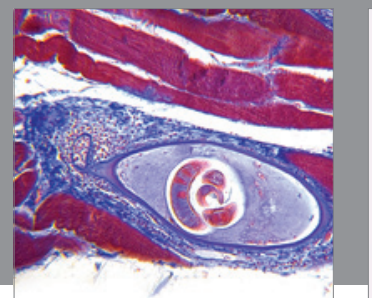

Gastroenterology

Research and Practice
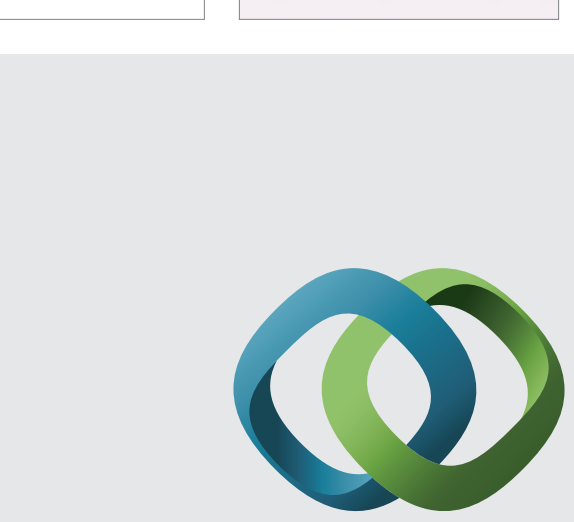

\section{Hindawi}

Submit your manuscripts at

http://www.hindawi.com
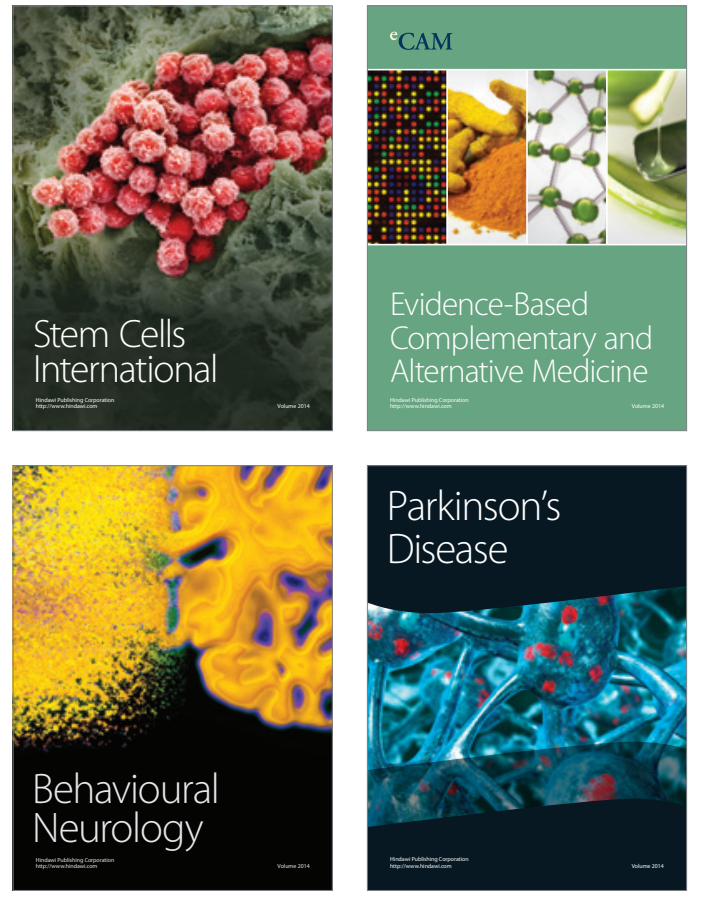
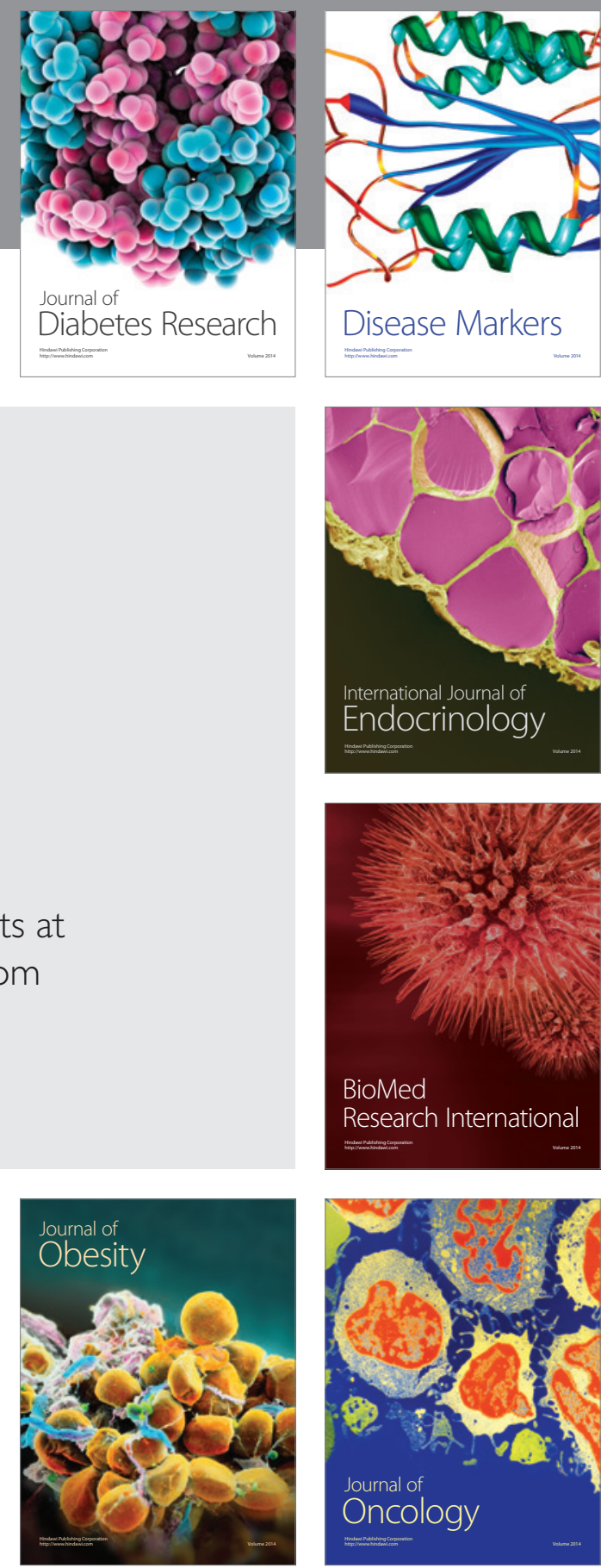

Disease Markers
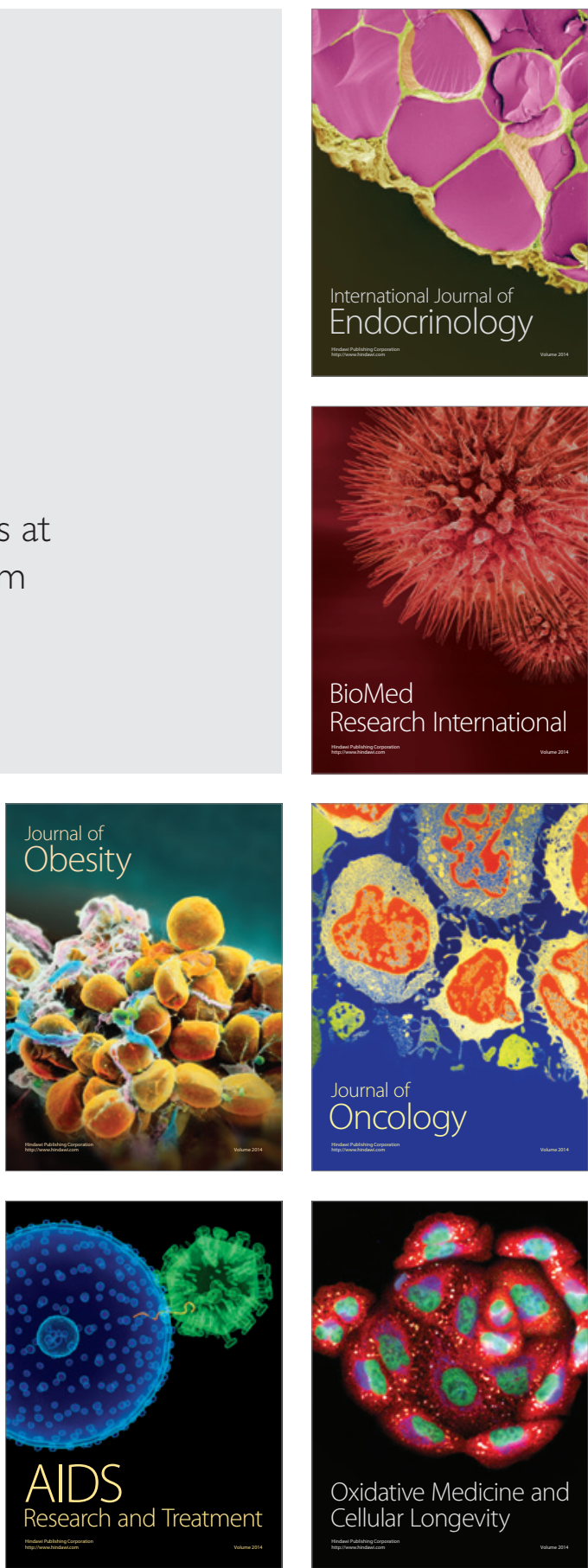